Research and Development Journal Of Education

Vol. 6 No. 1 Oktober 2019

p-ISSN 2406-9744

e-ISSN 2657-1056

\title{
PERBANDINGAN AKTIVITAS BELAJAR MELALUI MODEL PEMBELAJARAN KOOPERATIF TIPE GROUP INVESTIGATION DAN NUMBERED HEAD TOGETHER
}

\author{
Rendika Vhalery \\ Pendidikan Ekonomi, FIPPS, Universitas Indraprasta PGRI Jakarta \\ rendika.vhalery@unindra.ac.id
}

\begin{abstract}
Abstrak
Mata pelajaran ekonomi di sekolah menengah atas lebih dominan menggunakan model pembelajaran konvensional. Dimana guru menjadi pusat perhatian dan siswa hanya melihat atau mendengar penjelasan dari guru yang mengakibatkan siswa menjadi pasif. Ada banyak alternatif yang tersedia, salah satunya menggunakan model pembelajaran kooperatif. Pada penelitian ini, penulis menggunakan model pembelajaran kooperatif tipe group investigation dan numbered head together. Dengan tujuan untuk mengetahui apakah model pembelajaran kooperatif tipe group investigation dan numbered head together mempunyai pengaruh terhadap aktivitas belajar, serta untuk mengetahui apakah ada perbedaan aktivitas belajar melalui model pembelajaran kooperatif tipe group investigation dan numbered head together. Penelitian dilakukan di SMA Tri Dharma Palembang yang melibatkan 2 kelas yaitu kelas eksperimen 1 dan kelas eksperimen 2 . Hasil penelitian menunjukkan bahwa; 1) terdapat pengaruh model pembelajaran koperatif tipe group investigation terhadap aktivitas belajar siswa, 2) terdapat pengaruh model pembelajaran koperatif tipe numbered head together terhadap aktivitas belajar siswa, 3) terdapat perbedaan aktivitas belajar melalui model pembelajaran koperatif tipe group investigation dan numbered head together. Secara keseluruhan, model pembelajaran kooperatif tipe group investigation lebih baik untuk mengatasi masalah aktivitas belajar siswa daripada model pembelajaran kooperatif tipe numbered head together.
\end{abstract}

Kata kunci: Model Pembelajaran; Kooperatif; Group Investigation; Numbered Head Together; Aktivitas Belajar

\section{PENDAHULUAN}

Proses pembelajaran ekonomi di Sekolah Menengah Atas (SMA) lebih dominan menggunakan model pembelajaran konvensional. Dimana guru menjadi pusat perhatian dan siswa hanya melihat atau mendengar penjelasan dari guru. Hal ini dapat menimbulkan dampak negatif, dimana siswa akan menjadi pasif seperti mengantuk, malas, tidak mendengarkan, dan bahkan dapat menurunkan daya berpikir kritis siswa, sedangkan penjelasan dari guru tidak akan didengarkan oleh siswa (Asyari, Muhdhar, Susilo, \& Ibrohim, 2015; Vhalery \& Nofriansyah, 2018). Oleh sebab itu, diperlukan perkembangan dalam pembelajaran yang sesuai dengan karakteristik pembelajaran itu sendiri (Asyari et al., 2015).

Pembelajaran yang sesuai dengan karakteristik siswa biasanya berhubungan dengan model pembelajaran kooperatif. Astra, Wahyuni, \& Nasbey (2015) mengungkapkan bahwa model pembelajaran kolaboratif adalah pendekatan 
Research and Development Journal Of Education

Vol. 6 No. 1 Oktober 2019

p-ISSN 2406-9744

e-ISSN 2657-1056

pendidikan dalam proses pembelajaran yang melibatkan siswa untuk bekerja bersama dalam menyelesaikan masalah, menyelesaikan tugas, dan menciptakan produk. Selain itu, model pembelajaran kooperatif juga mengutamakan sistem pembelajaran dua arah (guru dan siswa) untuk mendapatkan feedback atau umpan balik (Vhalery, 2019). Ada beberapa jenis model pembelajaran kooperatif, diantaranya group investigation dan numbered head together.

Sojayapan \& Khlaisang (2018) menjelaskan bahwa group investigation atau investigasi kelompok merupakan bagian dari model pembelajaran kooperatif dan kolaboratif. Karena model pembelajaran investigasi kelompok akan membagi siswa kedalam beberapa golongan seperti keompok atas, kelompok menengah, dan kelompok bawah, atau kelompok-kelompok kecil. Model pembelajaran ini memotivasi siswa untuk berkomunikasi dan bekerjasama untuk mencapai tujuan tim. Saat menerapkan model pembelajaran investigasi kelompok, guru mempunyai beberapa peran yaitu, 1) menciptakan suasana dan kondisi yang nyaman untuk semua siswa yang berpartisipasi, 2) guru bertanggung jawab untuk membimbing proses penyelidikan dan memfasilitasi pembelajaran individu maupun kelompok, 3) guru terlibat sebagai bagian dari dinamika ruang kelas, 4) guru berperan sebagai peneliti aktif tentang apa yang terjadi di kelas dan sebagai pengamat kekuatan dan kelemahan siswa dalam proses melaksanakan penyelidikan (Damini, 2014).

Ulfah, Sahputra, \& Rasmawan (2014) Mengungkapkan bahwa model pembelajaran kooperatif tipe group investigation dapat diimplementasikan melalui beberapa langkah seperti; (1) pembentukan kelompok dan seleksi topik, pada tahap ini para siswa dibagi menjadi beberapa kelompok dan memilih topik yang telah disediakan untuk diinvestigasi, (2) perencanaan kooperatif, pada tahap ini guru dan siswa merencanakan tugas, prosedur, dan tujuan belajar sesuai topik dan subtopik yang telah dipilih, (3) Implementasi, pada tahap ini siswa melaksanakan rencana yang telah dirumuskan, (4) Analisis dan sintesis, pada tahap ini siswa menganalisis dan mensintesis berbagai informasi yang diperoleh untuk disajikan didepan kelas, (5) Presentasi hasil, pada tahap ini semua kelompok menyajikan hasil investigasi melalui presentasi yang menarik dari berbagai topik yang telah dipelajari, dan (6) Evaluasi, pada tahap ini guru dan siswa melakukan evaluasi mengenai kontribusi per individu dan per kelompok. 
Research and Development Journal Of Education

Vol. 6 No. 1 Oktober 2019

p-ISSN 2406-9744

e-ISSN 2657-1056

Penelitian model pembelajaran kooperatif tipe group investigation pernah dilakukan oleh Irwan \& Sani (2015) dengan judul "Efek Model Pembelajaran Kooperatif Tipe Group Investigation Dan Teamwork Skills Terhadap Hasil Belajar Fisika". Hasil penelitian menunjukkan bahwa; 1) terdapat perbedaan hasil belajar siswa melalui model kooperatif tipe group investigation dengan direct interuction dalam pembelajaran fisika, 2) terdapat perbedaan hasil belajar siswa antara kelompok siswa yang memiliki teamwork skills diatas rata-rata dengan kelompok siswa yang memiliki teamwork skills dibawah rata-rata, 3) terdapat interaksi antara model pembelajaran dengan teamwork skills dalam mempengaruhi hasil belajar fisika siswa.

Model pembelajaran kooperatif lainnya yaitu model pembelajaran numbered head together (NHT). Hadiyanti, Kusni, \& Suhito (2012) menjelaskan bahwa numbered head together merupakan model pembelajaran kooperatif yang memberikan kesempatan kepada siswa untuk bertukar gagasan. Adapun langkahlangkah untuk menerapkan model pembelajaran kooperatif tipe numbered head together yaitu; 1) tahap persiapan, guru mempersiapkan RPP dan materi yang berhubungan dengan model pembelajaran numbered head together; 2) pembentukan kelompok, guru membentuk kelompok belajar yang terdiri dari 3 5 orang dan memberi nomor kepada setiap siswa dan setiap kelompok; 3) setiap kelompok mempersiapkan sumber belajar; 4) diskusi masalah, setiap kelompok melakukan diskusi tentang suatu fenomena atau permasalahan yang dikemukakan oleh guru; 5) memanggil nomor siswa atau nomor kelompok, untuk menjawab pertanyaan dari guru tentang fenomena atau masalah yang telah dikemukakan; 6) kesimpulan, mengarahkan jawaban yang tepat dan menyimpulkan jawaban yang telah ada (Susilo \& Khabibah, 2017).

Penelitian model pembelajaran kooperatif tipe numbered head together juga pernah dilakukan oleh Rahmawati, Nugroho, \& Putra (2014) dengan judul "Penerapan Model Pembelajaran Kooperatif Tipe Numbered Head Together Berbasis Eksperimen Untuk Meningkatkan Keterampilan Proses Sains Siswa SMP”. Hasil penelitian mengungkapkan bahwa model pembelajaran kooperatif tipe numbered heads together dapat meningkatkan keterampilan proses sains siswa dalam kategori sedang. 
Research and Development Journal Of Education

Vol. 6 No. 1 Oktober 2019

p-ISSN 2406-9744

e-ISSN 2657-1056

Penelitian tentang model pembelajaran kooperatif tipe group investigation dan numbered head together telah banyak dilakukan. Namun, ada beberapa perbedaan pada penelitian ini dan penelitian sebelumnya, seperti 1) mata pelajaran yang digunakan; 2) apa yang dinilai dari model pembelajaran tersebut, contohnya: kebanyakan penulis menggunakan model pembelajaran untuk menilai, mengembangkan, atau meningkatkan hasil belajar (Yenni, 2016), motivasi belajar (Susilo \& Khabibah, 2017), keterampilan (Rahmawati et al., 2014), kemampuan membaca (Fanolong, Bugis, Azwan, Hanapi, \& Handayani, 2016), pemahaman (Hadiyanti et al., 2012), dan sebagainya; 3) jenjang pendidikan siswa; dan 4) perbandingan model pembelajaran kooperatif yang setara. Oleh sebab itu, peneliti tertarik untuk membandingkan dua model pembelajaran kooperatif pada jenjang pendidikan yang lebih tinggi dan menilai aspek lainnya. Judul yang diusulkan yaitu "Perbandingan Aktivitas Belajar Melalui Model Pembelajaran Kooperatif Tipe Group Investigation Dan Numbered Head Together".

Berdasarkan judul penelitian diatas, adapun rumusan masalah pada penelitian ini yaitu; (1) apakah ada pengaruh implementasi model pembelajaran kooperatif tipe group investigation terhadap aktivitas belajar siswa ?, (2) apakah ada pengaruh implementasi model pembelajaran kooperatif tipe numbered head together terhadap aktivitas belajar siswa ?, (3) apakah ada perbandingan aktivitas belajar siswa melalui model pembelajaran kooperatif tipe group investigation dan numbered head together?.

\section{METODOLOGI PENELITIAN}

\section{Jenis Penelitian}

Jenis penelitian ini adalah penelitian eksperimen dan komparatif menggunakan Completely Randomized Design. Completely Randomized Design merupakan desain eksperimen komparatif yang tanpa menggunakan kelas kontrol. Artinya, kedua kelas dijadikan kelas eksperimen. Menggunakan pre dan post observasi untuk mendapatkan data penelitian.

\section{Populasi dan Sampel}

Penelitian ini dilakukan di SMA Tri Dharma Palembang pada bulan Juli Agustus 2018. Populasi pada penelitian ini adalah semua siswa SMA Tri Dharma 
Research and Development Journal Of Education

Vol. 6 No. 1 Oktober 2019

p-ISSN 2406-9744

e-ISSN 2657-1056

Palembang yang berjumlah 410 orang. Rincian populasi penelitian dapat dilihat pada tabel dibawah ini:

Tabel 1

Populasi Penelitian

\begin{tabular}{|c|c|c|}
\hline Kelas & Jurusan & Jumlah siswa \\
\hline \multirow[t]{6}{*}{$X$} & IPA 1 & 28 \\
\hline & IPA 2 & 25 \\
\hline & IPA 3 & 28 \\
\hline & IPS 1 & 28 \\
\hline & IPS 2 & 26 \\
\hline & IPS 3 & 35 \\
\hline \multirow[t]{4}{*}{ XI } & IPA 1 & 36 \\
\hline & IPA 2 & 35 \\
\hline & IPS 1 & 36 \\
\hline & IPS 2 & 35 \\
\hline \multirow[t]{4}{*}{ XII } & IPA 1 & 31 \\
\hline & IPA 2 & 26 \\
\hline & IPS 1 & 41 \\
\hline & & 410 \\
\hline
\end{tabular}

Sumber: Arsip Administrasi SMA Tri Dharma Semester Ganjil 2018/2019

Teknik pengambilan sampel pada penelitian ini menggunakan purposive teknik sampling. Peneliti menggunakan kelas XI IPS 1 dan XI IPS 2 dikarenakan kondisi sistem belajar disekolah sudah stabil. Kelas XI IPS 1 sebagai kelas eksperimen 1. Kelas XI IPS 2 sebagai kelas eksperimen 2.

\section{Rancangan Eksperimen}

1. Tahap Persiapan

a. Memilih dua kelas yaitu kelas eksperimen 1 dan kelas eksperimen 2 sebagai sampel penelitian.

b. Membuat rancangan pembelajaran serta mempersiapkan sumber belajar untuk melaksanakan proses pembelajaran.

c. Menggunakan model pembelajaran kooperatif tipe group investigation di kelas eksperimen 1 dan menggunakan model pembelajaran kooperatif tipe numbered head together di kelas eksperimen 2.

d. Membuat instrument penelitian (lembar observasi).

e. Menguji validitas dan reliabilitas instrument penelitian.

2. Tahap Pelaksanaan

a. Melakukan proses pembelajaran dengan menerapkan model pembelajaran kooperatif tipe group investigation dan tipe numbered head together. 
Research and Development Journal Of Education

Vol. 6 No. 1 Oktober 2019

p-ISSN 2406-9744

e-ISSN 2657-1056

b. Memberikan materi pelajaran tentang ketenagakerjaan kepada siswa.

c. Penilaian observasi pada setiap pertemuan tentang penerapan model pembelajaran kooperatif dan aktivitas belajar siswa dalam pembelajaran.

3. Tahap Penyelesaian

a. Menganalisis data aktivitas belajar siswa dari hasil lembar observasi.

b. Menganalisis data penerapan model pembelajaran kooperatif tipe group investigation dan tipe numbered head together.

c. Men-tabulasi data penelitian dan menginterprestasikan data penelitian yang telah dikumpulkan.

d. Pengujian hipotesis.

e. Membuat simpulan hasil penelitian.

\section{Teknik Pengumpulan Data}

1. Observasi, pengumpulan data observasi dilakukan di kelas eksperimen 1 dan kelas eksperimen 2 menggunakan lembar observasi dengan cara memberi tanda checklist $(\sqrt{ })$ untuk memperoleh data tentang aktivitas belajar siswa dan penerapan model pembelajaran kooperatif tipe group investigation dan tipe numbered head together.

2. Dokumentasi, pengumpulan data dokumentasi digunakan untuk menunjang proses penelitian dan proses pembelajaran selama pengimplementasian model pembelajaran kooperatif.

\section{Teknik Analisis Data}

Teknik analisis data menggunakan bantuan software SPSS versi 24.0 untuk mempermudah proses perhitungan data penelitian. Adapun tahap-tahap analisis data yang dilakukan dirincikan sebagai berikut:

1. Analisis Deskriptif

2. Uji Prasyarat
a. Uji Normalitas Data
b. Uji Homogenitas Data
c. Uji Hipotesis

\section{HASIL DAN PEMBAHASAN}

\section{Hasil Penelitian}

\subsection{Deskripsi Data Penelitian}


Research and Development Journal Of Education

Vol. 6 No. 1 Oktober 2019

p-ISSN 2406-9744

e-ISSN 2657-1056

Tabel 2

Hasil Uji Statistik Deskriptif

\begin{tabular}{cc|c|c|c|c} 
Kelas & N & Minimum & Maximum & Mean & Std. Deviation \\
\hline Pre-Eksperimen1 & 35 & 50 & 79 & 60,29 & 7,327 \\
\hline Post-Eksperimen1 & 35 & 80 & 95 & 85,91 & 4,231 \\
\hline Pre-Eksperimen2 & 36 & 51 & 72 & 61,81 & 6,373 \\
\hline Post-Eksperimen2 & 36 & 67 & 89 & 78,19 & 5,711 \\
\hline Valid N (listwise) & 35 & & & & \\
\hline \multicolumn{2}{l}{ Sumber: Olahan Data Primer 2018 }
\end{tabular}

\subsubsection{Deskripsi Data Observasi di Kelas Eksperimen 1}

Observasi dilakukan sebelum dan sesudah diberi perlakuan model pembelajaran kooperatif tipe group investigation. Berikut tabel hasil observasi aktivitas belajar dikelas eksperimen-1 :

Tabel 3.

Distribusi Frekuensi Aktivitas Belajar di Kelas Eksperimen 1

\begin{tabular}{ccccc}
\hline Data & Skor terkecil & Skor terbesar & Rerata & Kriteria \\
\hline Pre & 50 & 79 & $60,3 \%$ & Cukup Aktif \\
Post & 80 & 95 & $85,9 \%$ & Sangat Aktif \\
\hline
\end{tabular}

Sumber: Olahan Data Primer 2018

Tabel 4.

Rincian Aktivitas Belajar di Kelas Eksperimen 1

\begin{tabular}{ccccccc}
\hline \multirow{2}{*}{ No. } & \multirow{2}{*}{ Skor yang diperoleh } & Kategori & Pre & \multicolumn{2}{c}{ Post } \\
\hline 1 & $86-100$ & Sangat Aktif & - & Siswa & $\%$ \\
2 & $71-85$ & Aktif & 3 & - & 17 & 48,6 \\
3 & $56-70$ & Cukup Aktif & 21 & 60 & 18 & 51,4 \\
4 & $41-55$ & Kurang Aktif & 11 & 31,4 & - & - \\
5 & $0-40$ & Sangat Kurang Aktif & - & - & - & - \\
& & & 35 & 100 & 36 & 100 \\
\hline
\end{tabular}

Sumber: Olahan Data Primer 2018

Berdasarkan tabel 4 disimpulkan bahwa sebelum diberi perlakuan model pembelajaran kooperatif tipe group investigation, siswa sudah memiliki aktivitas belajar yang cukup aktif. Setelah diberi perlakuan model pembelajaran kooperatif tipe group investigation, aktivitas belajar siswa meningkat menjadi sangat aktif. Peningkatan aktivitas belajar pada kelas eksperimen 1 diketahui sebesar 25,6\%.

\subsubsection{Deskripsi Data Observasi di Kelas Eksperimen 2}

Observasi pada kelas eksperimen 2 sebelum dan sesudah diberi perlakuan model pembelajaran kooperatif tipe numbered head together dapat dilihat pada tabel berikut ini: 
Research and Development Journal Of Education

Vol. 6 No. 1 Oktober 2019

Tabel 5.

Distribusi Frekuensi Aktivitas Belajar di Kelas Eksperimen 2

\begin{tabular}{ccccc}
\hline Data & Skor terkecil & Skor terbesar & Rerata & Kriteria \\
\hline Pre & 51 & 72 & $61,8 \%$ & Aktif \\
Post & 67 & 89 & $78,2 \%$ & Aktif \\
\hline
\end{tabular}

Sumber: Olahan Data Primer 2018

Tabel 6.

Rincian Aktivitas Belajar di Kelas

\begin{tabular}{ccccccc}
\hline \multirow{2}{*}{ No. } & \multirow{2}{*}{ Skor yang diperoleh } & \multirow{2}{*}{ Kategori } & \multicolumn{2}{c}{ Pre } & \multicolumn{3}{c}{ Post } \\
& & Siswa & \% & Siswa & \% \\
\hline 1 & $86-100$ & Sangat Aktif & - & - & 17 & 48,6 \\
2 & $71-85$ & Aktif & 12 & 34,3 & 18 & 51,4 \\
3 & $56-70$ & Cukup Aktif & 23 & 65,7 & - & - \\
4 & $41-55$ & Kurang Aktif & - & - & - & - \\
5 & $0-40$ & Sangat Kurang Aktif & - & - & - & - \\
& & & 35 & 100 & 35 & 100 \\
\hline
\end{tabular}

Sumber: Olahan Data Primer 2018

Berdasarkan tabel 6 disimpulkan bahwa sebelum diberi perlakuan model pembelajaran kooperatif tipe numbered head together, siswa sudah memiliki aktivitas belajar yang aktif. Setelah diberi perlakuan model pembelajaran kooperatif tipe numbered head together, aktivitas belajar siswa terus meningkat menjadi sangat aktif. Peningkatan aktivitas belajar pada kelas eksperimen 2 sebesar $16,4 \%$.

\subsubsection{Perbandingan Deskripsi Data Observasi di Kelas Eksperimen 1 dan 2}

Perbandingan data pre dan post observasi pada kelas eksperimen 1 dan kelas eksperimen 2 dapat digambarkan diagram sebagai berikut:

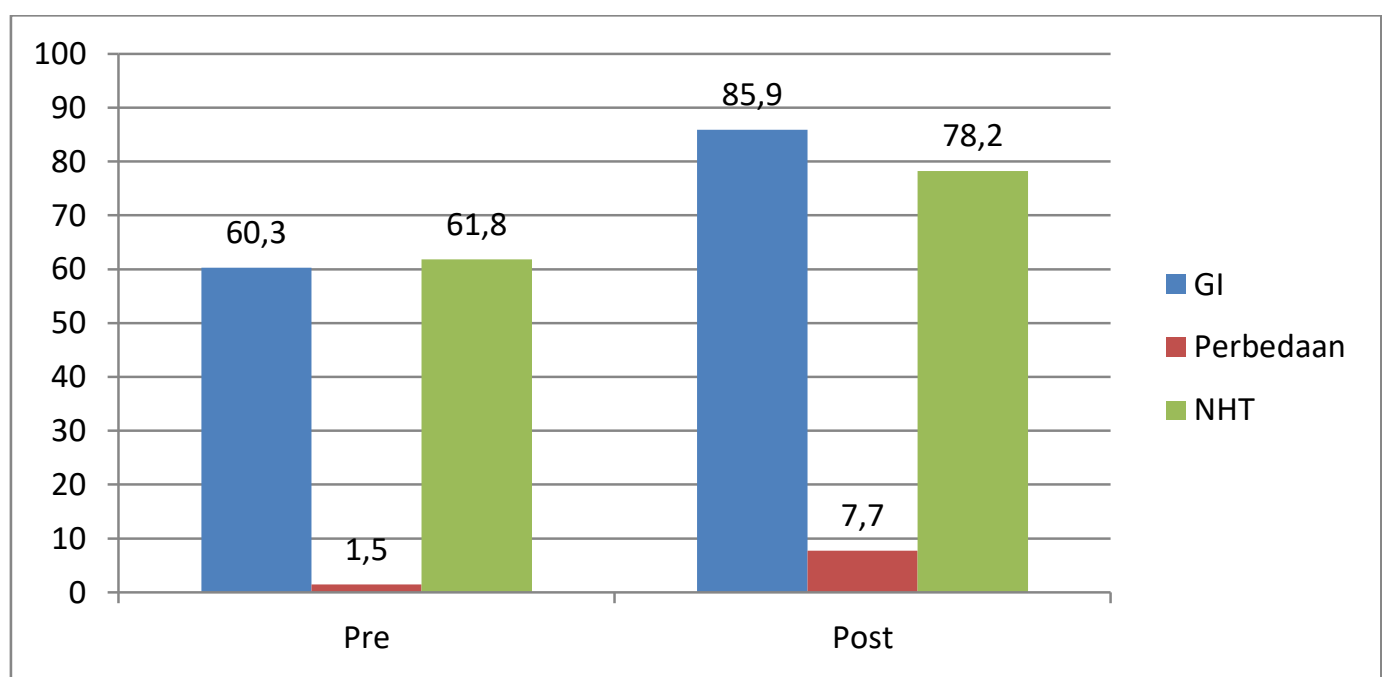

Sumber: Olahan Data Primer 2018

Gambar 1.

Perbandingan Aktivitas Belajar di Kelas Eksperimen 1 dan 2 
Research and Development Journal Of Education

Vol. 6 No. 1 Oktober 2019

p-ISSN 2406-9744

e-ISSN 2657-1056

\subsection{Uji Asumsi Klasik}

\subsubsection{Uji Normalitas Data}

Tabel 7.

Hasil Uji Normalitas

\begin{tabular}{lcccccccc}
\hline \multirow{2}{*}{ Variabel } & \multirow{2}{*}{ Kelas } & \multicolumn{2}{c}{ Kolmogorov-Smirnov } & \multicolumn{3}{c}{ Shapiro-Wilk } \\
& \multirow{2}{*}{ Pre-Eks1 } & Statistic & df & Sig. & Statistic & df & Sig. \\
\hline \multirow{4}{*}{ Aktivitas Belajar } & Post-Eks1 &, 108 & 35 &, $200^{*}$ &, 954 & 35 &, 146 \\
& Pre-Eks2 &, 109 & 36 &, $200^{*}$ &, 949 & 35 &, 107 \\
& Post-Eks2 &, 128 & 36 &, 143 &, 963 & 36 &, 103 \\
\multicolumn{2}{c}{ Keterangan } & \multicolumn{3}{c}{ Normal } \\
\hline
\end{tabular}

Sumber: Olahan Data Primer 2018

\subsubsection{Uji Homogenitas Data}

Tabel 8.

Hasil Uji Homogenitas

\begin{tabular}{cccccc|c}
\hline & & Levene Statistic & df1 & df2 & Sig. & Keterangan \\
\hline \multirow{2}{*}{ Aktivitas } & Based on Mean & 1,223 & 1 & 69 &, 273 & \\
Belajar & Based on Median & 1,196 & 1 & 69 &, 278 & \multirow{2}{*}{ Homogen } \\
& Based on Median and with adjusted df & 1,196 & 1 & 60,792 &, 279 & \\
& Based on trimmed mean & 1,241 & 1 & 69 &, 269 & \\
\hline
\end{tabular}

Sumber: Olahan Data Primer 2018

\subsection{Uji Hipotesis}

Tabel 9.

Hasil Uji Hipotesis

\begin{tabular}{|c|c|c|c|c|c|c|c|c|c|}
\hline & & \multirow[b]{3}{*}{ Mean } & \multicolumn{4}{|c|}{ Paired Differences } & \multirow{3}{*}{$\mathbf{t}$} & \multirow{3}{*}{ df } & \multirow{3}{*}{$\begin{array}{l}\text { Sig. (2- } \\
\text { tailed) }\end{array}$} \\
\hline & & & \multirow{2}{*}{$\begin{array}{c}\text { Std. } \\
\text { Deviation } \\
\end{array}$} & \multirow{2}{*}{$\begin{array}{c}\text { Std. Error } \\
\text { Mean }\end{array}$} & \multicolumn{2}{|c|}{$\begin{array}{l}\text { 95\% Confidence Interval of } \\
\text { the Difference }\end{array}$} & & & \\
\hline & & & & & Lower & Upper & & & \\
\hline Pair 1 & $\begin{array}{l}\text { Pre-Eksperimen1 - Post- } \\
\text { Eksperimen1 }\end{array}$ & $-25,629$ & 8,958 & 1,514 & $-28,706$ & $-22,551$ & $-16,926$ & 34 & ,000 \\
\hline Pair 2 & $\begin{array}{l}\text { Pre-Eksperimen2 - Post- } \\
\text { Eksperimen2 }\end{array}$ & $-16,389$ & 7,897 & 1,316 & $-19,061$ & $-13,717$ & $-12,452$ & 35 & ,000 \\
\hline
\end{tabular}

Sumber: Olahan Data Primer 2018

Berdasarkan hasil output SPSS 24.0 pada tabel 9 (uji hipotesis menggunakan uji paired sample t-test) diatas dapat disimpulkan sebagai berikut:

a. Kelas eksperimen 1 yang terdiri dari pre dan post observasi mempunyai nilai signifikansi (2-tailed) sebesar 0,000. Sesuai dengan ketentuan pengujian hipotesis $0,000<0,050$, maka $\mathrm{H}_{01}$ ditolak dan $\mathrm{Ha}_{1}$ diterima. Artinya, terdapat 
Research and Development Journal Of Education

Vol. 6 No. 1 Oktober 2019

p-ISSN 2406-9744

e-ISSN 2657-1056

pengaruh implementasi model pembelajaran kooperatif tipe group investigation pada aktivitas belajar siswa.

b. Kelas eksperimen 2 yang terdiri dari pre dan post observasi mempunyai nilai signifikansi (2-tailed) sebesar 0,000. Sesuai dengan ketentuan pengujian hipotesis $0,000<0,050$, maka $\mathrm{H}_{02}$ juga ditolak dan $\mathrm{Ha}_{2}$ diterima. Artinya, terdapat pengaruh implementasi model pembelajaran kooperatif tipe numbered head together pada aktivitas belajar siswa.

Selanjutnya, untuk mengetahui hasil komparatif dari penggunaan kedua model pembelajaran kooperatif, dapat dilihat pada tabel berikut ini:

Tabel 10.

Hasil Uji Hipotesis Komparatif

\begin{tabular}{|c|c|c|c|c|c|c|c|c|c|c|}
\hline & & $\begin{array}{r}\text { Le } \\
\text { Equa }\end{array}$ & $\begin{array}{l}\text { Test for } \\
\text { Variances }\end{array}$ & \multicolumn{7}{|c|}{ t-test for Equality of Means } \\
\hline & & \multirow[t]{2}{*}{$\mathbf{F}$} & \multirow[t]{2}{*}{ Sig. } & \multirow[t]{2}{*}{$\mathbf{T}$} & \multirow[t]{2}{*}{ Df } & \multirow{2}{*}{$\begin{array}{c}\text { Sig. } \\
\text { (2-tailed) }\end{array}$} & \multirow{2}{*}{$\begin{array}{c}\text { Mean } \\
\text { Difference }\end{array}$} & \multirow{2}{*}{$\begin{array}{l}\text { Std. Error } \\
\text { Difference }\end{array}$} & \multicolumn{2}{|c|}{$\begin{array}{l}\text { 95\% Confidence Interva } \\
\text { of the Difference }\end{array}$} \\
\hline & & & & & & & & & Lower & Upper \\
\hline \multirow{2}{*}{$\begin{array}{l}\text { Aktivitas } \\
\text { Belajar }\end{array}$} & $\begin{array}{c}\text { Equal variances } \\
\text { assumed }\end{array}$ & 1,223 &, 273 & 6,457 & 69 &, 000 & 7,720 & 1,196 & 5,335 & 10,105 \\
\hline & $\begin{array}{c}\text { Equal variances } \\
\text { not assumed }\end{array}$ & & & 6,484 & 64,510 &, 000 & 7,720 & 1,191 & 5,342 & 10,098 \\
\hline
\end{tabular}

Sumber: Olahan Data Primer 2018

Berdasarkan hasil output SPSS 24.0 pada tabel 10 (hasil uji hipotesis komparatif) diketahui bahwa nilai aktivitas belajar pada equal variances assumed didapat signifikansi (2-tailed) sebesar 0,000 $<0,050$, berdasarkan ketentuan pengujian hipotesis maka $\mathrm{H}_{03}$ ditolak dan $\mathrm{Ha}_{3}$ diterima. Artinya, terdapat perbandingan model pembelajaran kooperatif tipe group investigation dengan tipe numbered head together pada aktivitas belajar siswa.

\section{Pembahasan}

\subsection{Pengaruh Implementasi Model Pembelajaran Kooperatif Tipe Group}

\section{Investigation Pada Aktivitas Belajar Siswa}

Hasil penelitian menunjukkan bahwa model pembelajaran kooperatif tipe group investigation berpengaruh terhadap aktivitas belajar siswa. Adanya pengaruh model pembelajaran kooperatif tipe group investigation pada aktivitas belajar dikarenakan aktivitas belajar ditekankan pada keterampilan berpikir kritis dan kompleks (intelektual, sikap, gaya belajar, dan gaya) pada saat proses 
Research and Development Journal Of Education

Vol. 6 No. 1 Oktober 2019

p-ISSN 2406-9744

e-ISSN 2657-1056

pembelajaran berlangsung (Khaeriyah, 2016; Khafid, 2010). Oleh sebab itu, model pembelajaran kooperatif tipe group investigation mempunyai dampak terhadap aktivitas belajar siswa secara langsung.

Ada beberapa temuan peneliti pada saat mengimplementasikan model pembelajaran kooperatif tipe group investigation. Model pembelajaran kooperatif tipe group investigation mempunyai kelebihan seperti menghidupkan suasana kelas (yang awalnya pasif atau kaku menjadi aktif atau interaktif), menumbuhkan rasa percaya diri, menumbuhkan jiwa sosial antara siswa dengan siswa serta siswa dengan guru, menimbulkan interaksi, berbagi ide, belajar bersama, meningkatkan daya berpikir kritis siswa, membuat proses pembelajaran yang menyenangkan, dan menghilangkan perbedaan status antar siswa. Namun, ada juga beberapa kekurangannya seperti menghabiskan banyak waktu apabila tidak dibatasi, menimbulkan suara gaduh atau dapat mengganggu kelas lain, beberapa siswa menjadi ketergantungan (tidak berkontribusi dalam berpikir atau bertindak). Secara keseluruhan, model pembelajaran kooperatif tipe group investigation sangat cocok digunakan pada saat aktivitas belajar siswa mulai pasif atau kaku.

\subsection{Pengaruh Implementasi Model Pembelajaran Kooperatif Tipe numbered head together Pada Aktivitas Belajar Siswa}

Hasil penelitian menunjukkan bahwa model pembelajaran kooperatif tipe numbered head together berpengaruh terhadap aktivitas belajar siswa. Adanya pengaruh model pembelajaran kooperatif tipe numbered head together pada aktivitas belajar dikarenakan model pembelajaran kooperatif tipe numbered head together mampu meningkatkan pencapaian siswa melalui interaksi multi arah (siswa ke/dan guru) sehingga siswa tidak menjadi pasif di kelas (Pietersz \& Saragih, 2010). Di sisi lain, model pembelajaran kooperatif tipe numbered head together berguna untuk meningkatkan ranah kognitif, afektif, dan psikomotorik siswa sesuai dengan kurikulum terbaru (kurikulum 2013 revisi 2017 dsb.).

Ada beberapa temuan peneliti pada saat mengimplementasikan model pembelajaran kooperatif tipe numbered head together. Model pembelajaran kooperatif tipe numbered head together mempunyai kelebihan seperti proses pembelajaran menjadi interaktif, meningkatkan motivasi, menumbuhkan jiwa sosial, menciptakan interaksi multi arah, bertukar pendapat, belajar bersama, meningkatkan kekompakan grup, dan menghilangkan perbedaan antar siswa. 
Research and Development Journal Of Education

Vol. 6 No. 1 Oktober 2019

p-ISSN 2406-9744

e-ISSN 2657-1056

Namun, ada juga beberapa kekurangannya seperti menimbulkan suara gaduh atau dapat mengganggu kelas lain, beberapa siswa ada yang cemburu, serta sulitnya mengontrol setiap siswa. Secara keseluruhan, model pembelajaran kooperatif tipe numbered head together sangat cocok digunakan untuk mengatasi permasalahan aktivitas belajar siswa.

\subsection{Perbandingan Aktivitas Belajar Melalui Model Pembelajaran Kooperatif Tipe group investigation dan numbered head together}

Hasil penelitian menunjukkan bahwa ada perbandingan aktivitas belajar siswa melalui model pembelajaran kooperatif tipe group investigation dan numbered head together. Perbandingan data pada kelas eksperimen antar model pembelajaran kooperatif menunjukkan perbedaan sebesar $1,5 \%$ (pre) yang didominasi oleh model pembelajaran kooperatif tipe numbered head together dan sebesar 7,7\% (post) yang didominasi oleh model pembelajaran kooperatif tipe group investigation. Model pembelajaran kooperatif tipe group investigation dapat meningkatkan aktivitas belajar siswa sebesar 25,6\%. Sedangkan model pembelajaran kooperatif tipe numbered head together dapat meningkatkan aktivitas belajar siswa sebesar 16,4\%. Secara keseluruhan, model pembelajaran kooperatif tipe group investigation membuat aktivitas belajar siswa menjadi lebih baik daripada model pembelajaran kooperatif tipe numbered head together.

\section{PENUTUP}

\section{Kesimpulan}

Berdasarkan hasil penelitian eksperimen dan kesimpulan diatas, dapat disimpulkan bahwa:

a. Model pembelajaran kooperatif tipe group investigation berpengaruh terhadap aktivitas belajar siswa. Dampak model pembelajaran kooperatif tipe group investigation dapat dilihat dari perubahan aktivitas belajar siswa yang awalnya berada pada kategori "cukup" atau normal menjadi "aktif".

b. Model pembelajaran kooperatif tipe Numbered Head Together berpengaruh terhadap aktivitas belajar siswa. Dampak model pembelajaran kooperatif tipe numbered head together dapat dilihat dari aktivitas belajar siswa terkategori "aktif". 
Research and Development Journal Of Education

Vol. 6 No. 1 Oktober 2019

p-ISSN 2406-9744

e-ISSN 2657-1056

c. Adanya perbandingan aktivitas belajar melalui model pembelajaran kooperatif tipe group investigation dan numbered head together.

d. Menggunakan model pembelajaran kooperatif tipe group investigation lebih baik untuk mengatasi masalah aktivitas belajar siswa daripada menggunakan model pembelajaran kooperatif tipe numbered head together.

\section{Saran}

Adapun beberapa saran yang dapat diberikan dalam penelitian ini, yaitu:

a. Untuk menggunakan model pembelajaran kooperatif ini dibutuhkan waktu yang banyak, sehingga guru harus bisa membagi waktu belajar dengan tepat dan sesuai dengan kapasitas siswanya.

b. Penggunaan model pembelajaran kooperatif yang aktif ini sangat cocok untuk diterapkan pada proses pembelajaran yang menjelang siang hari atau di/pada sekolah yang mempunyai jadwal masuk sekolah siang hari.

c. Penerapan reward dan punishment diberlakukan untuk memicu motivasi belajar siswa agar siswa menjadi lebih semangat.

d. Untuk peneliti berikutnya diharapkan menggunakan model pembelajaran kooperatif tipe lainnya atau membandingkan salah satu model pembelajaran kooperatif dalam penelitian ini dengan model pembelajaran kooperatif lainnya

\section{DAFTAR PUSTAKA}

Astra, I. M., Wahyuni, C., \& Nasbey, H. (2015). Improvement of Learning Process and Learning Outcomes in Physics Learning by using Collaborative Learning Model of Group Investigation at High School ( grade X , SMAN 14 Jakarta ). Journal of Education and Practice, 6(11), 75-80.

Asyari, M., Muhdhar, M. H. I. Al, Susilo, H., \& Ibrohim. (2015). Improving critical thinking skills through the integration of problem based learning and group investigation. International Journal for Lesson and Learning Studies, $5(1), 36-44$.

Damini, M. (2014). How the Group Investigation model and the Six-Mirror model changed teachers' roles and teachers' and students' attitudes towards diversity. Intercultural Education, 25(3), 197-205. https://doi.org/10.1080/14675986.2014.917794

Fanolong, T., Bugis, R., Azwan, A., Hanapi, H., \& Handayani, N. (2016). The Students' Reading Ability Improvement Through Numbered Head Together (Nht) Technique, 1-10.

Hadiyanti, R., Kusni, \& Suhito. (2012). Keefektifan Pembelajaran Kooperatif 
Research and Development Journal Of Education

Vol. 6 No. 1 Oktober 2019

p-ISSN 2406-9744

e-ISSN 2657-1056

Numberedhead Together Terhadap Kemampuan Pemahaman Konsep. Unnes Journal of Mathematics Education, 1(1). Retrieved from http://journal.unnes.ac.id/sju/index.php/ujme

Irwan, N., \& Sani, R. A. (2015). Efek Model Pembelajaran Kooperatif Tipe Group Investigation Dan Teamwork Skills Terhadap Hasil Belajar Fisika. Jurnal Pendidikan Fisika, 4(1), 41-48. https://doi.org/10.22611/jpf.v4i1.2567

Khaeriyah, F. (2016). Peningkatan Hasil Belajar Ilmu Pengetahuan Sosial Melalui Metode Cooperative Learning Teknik Grup Investigasi. Jurnal Pendidikan Dasar, 7(2), 209-224.

Khafid, S. (2010). Pembelajaran Kooperatif Model Investigasi Kelompok, Gaya Kognitif, Dan Hasil Belajar Geografi. Jurnal Ilmu Pendidikan, 17(1), 7378.

Pietersz, F., \& Saragih, H. (2010). Pengaruh Penggunaan Pembelajaran Kooperatif Tipe Numbered Head Together Terhadap Pencapaian Matematika Siswa di SMP Negeri 1 Cisarua. Prosiding Seminar Nasional Fisika, 432-438.

Rahmawati, D., Nugroho, S. ., \& Putra, N. M. D. (2014). Penerapan Model Pembelajaran Kooperatif Tipe Numbered Head Together Berbasis Eksperimen Untuk Meningkatkan Keterampilan Proses Sains Siswa SMP D. Unnes Physic Education Journal, 3(1).

Sojayapan, C., \& Khlaisang, J. (2018). The effect of a flipped classroom with online group investigation on students' team learning ability. Kasetsart Journal of Social Sciences, $\quad$ pp. $1-6$. https://doi.org/10.1016/j.kjss.2018.02.003

Susilo, Y., \& Khabibah, S. (2017). Peningkatan Motivasi Belajar Siswa Melalui Model Pembelajaran Kooperatif Tipe Numbered Head Together ( Nht ) Materi Ajar Perbandingan Dan Fungsi Trigonometri Pada Siswa Kelas X. MATHEdunesa, 2(2).

Ulfah, A., Sahputra, R., \& Rasmawan, R. (2014). Pengaruh Model Pembelajaran Group Investigation Terhadap Keterampilan Proses Sains Pada Materi Koloid di SMA. Jurnal Pendidikan Dan Pembelajaran, 3(10), 1-11. Retrieved from http://jurnal.untan.ac.id/index.php/jpdpb/article/view/7535

Vhalery, R. (2019). Perbandingan Model Pembelajaran Kooperatif Tipe Gallery walk dengan Tipe Learning together pada Aktivitas Belajar Peserta Didik di SMA Tri Dharma Palembang. Jurnal Inovasi Pendidikan Ekonomi (Vol. 9).

Vhalery, R., \& Nofriansyah, -. (2018). Cooperative Learning in the Learning Activity of Students. International Journal of Scientific and Research $\begin{array}{lll}\text { Publications } & \text { (IJSRP), } & \text { 8(9), }\end{array}$ https://doi.org/10.29322/IJSRP.8.9.2018.p8110

Yenni, R. F. (2016). Penggunaan Metode Numbered Head Together (NHT) Dalam Pembelajaran Matematika. JPPM, 9(2), 263-267. 